Research Article

\title{
Excitation-Dependent Fluorescence Quantum Yield for Freshwater Chromophoric Dissolved Organic Matter from Northern Russian Lakes
}

\author{
Svetlana Patsaeva $\left({ }^{D},{ }^{1}\right.$ Daria Khundzhua, ${ }^{1}$ Oleg A. Trubetskoj, ${ }^{2}$ and \\ Olga E. Trubetskaya ${ }^{3}$ \\ ${ }^{1}$ Faculty of Physics, Lomonosov Moscow State University, Leninskie Gory 1, Moscow 119992, Russia \\ ${ }^{2}$ Institute of Basic Biological Problems, Russian Academy of Sciences, Pushchino, Moscow Region, Russia \\ ${ }^{3}$ Branch of Shemyakin and Ovchinnikov Institute of Bioorganic Chemistry, Russian Academy of Sciences, \\ Pushchino, Moscow Region, Russia
}

Correspondence should be addressed to Svetlana Patsaeva; spatsaeva@mail.ru

Received 10 February 2018; Revised 11 April 2018; Accepted 2 May 2018; Published 4 June 2018

Academic Editor: Arnaud Cuisset

Copyright $\odot 2018$ Svetlana Patsaeva et al. This is an open access article distributed under the Creative Commons Attribution License, which permits unrestricted use, distribution, and reproduction in any medium, provided the original work is properly cited.

Advanced fluorescence analysis within the wide range of excitation wavelengths from 230 to $510 \mathrm{~nm}$ accompanied with chromatography was used to study natural chromophoric dissolved organic matter (CDOM) from three freshwater Karelian lakes. The influence of excitation wavelength $\left(\lambda_{\text {ex }}\right)$ on fluorescence quantum yield and emission maximum position was determined. The CDOM fluorescence quantum yield has reached a minimum at $\lambda_{\text {ex }} \sim 270-280 \mathrm{~nm}$ and a maximum at $\lambda_{\text {ex }} \sim 340-360 \mathrm{~nm}$. It was monotonously decreasing after $370 \mathrm{~nm}$ towards longer excitation wavelengths. Analytical reversed-phase high-performance liquid chromatography with multiwavelength fluorescence detector characterized distribution of fluorophores between hydrophilic/hydrophobic CDOM parts. This technique revealed "hidden" protein-like fluorophores for some CDOM fractions, in spite of the absence of protein-like fluorescence in the initial CDOM samples. The humic-like fluorescence was documented for all hydrophilic and hydrophobic CDOM chromatographic peaks, and its intensity was decreasing along with peaks' hydrophobicity. On contrary, the protein-like fluorescence was found only in the hydrophobic peaks, and its intensity was increasing along with peaks' hydrophobicity. This work provides new data on the CDOM optical properties consistent with the formation of supramolecular assemblies controlled by association of low-molecular size components. In addition, these data are very useful for understanding the CDOM function in the environment.

\section{Introduction}

Chromophoric dissolved organic matter (CDOM) naturally occurring in all aquatic environments is colored and contains materials of different molecular sizes (MSs). These chemically complex compounds of irregular structure exert physical-chemical properties of water, affect sorption capacity, and control transport of pollutants in different environments. The CDOM absorbs light in the UV and shortwave visible ranges and thus governs the optical properties for both freshwater and marine aquatic ecosystems directly influencing the spectral quality of the underwater light field. Because of its absorbance in the UV, it can protect aquatic organisms being damaged by the UV radiation [1].

Emittance of fluorescence under UV light is one of the main properties of aquatic CDOM that allows its fast and highly sensitive analysis [2-8]. Fluorescence measurements provide essential information about the chemical structure of aquatic CDOM and require small sample amounts. It can be applied also in the remote sensing using lidar systems for CDOM fluorescence detection from aboard the ship or aircraft. As it is currently accepted, the fluorescence of aquatic CDOM consists of two main bands, the so-called protein-like and humic-like fluorescence coming from two main groups of fluorophores $[2,3]$. Protein-like 
fluorophores usually have an excitation and emission maxima below 305 and $380 \mathrm{~nm}$, respectively. The other group corresponds to humic-like fluorophores and shows emission within the wavelength range $380-600 \mathrm{~nm}$ upon excitation within the wavelength range $230-550 \mathrm{~nm}$. Along with changing the excitation wavelength $\left(\lambda_{\mathrm{ex}}\right)$ from 270 to $310 \mathrm{~nm}$, the humic-like emission maximum shifts towards shorter wavelengths. Such a shift of the emission maximum with increasing excitation wavelength was named the "blue shift" [4]. This phenomenon has been described for various types of natural waters [5-8] and during transformations of humic substances caused by microscopic fungi [9].

The fluorescence quantum yield of CDOM has been an object of several studies where it was found that it may vary depending on the excitation wavelength $[7,10,11]$. Its values under excitation at discrete wavelengths 270,310 , and $355 \mathrm{~nm}$ were measured for the fractions of different MSs obtained by filtration on $5 \mathrm{~nm}$ pore size membrane in riverine $\mathrm{CDOM}[5,6]$ and various freshwater and marine samples [7]. Low-MS fractions $(<5 \mathrm{~nm})$ demonstrated higher fluorescence quantum yield in comparison with the high-MS fractions $(>5 \mathrm{~nm})$. Fluorescence quantum yield was found essentially dependent of excitation wavelength with increasing its value along with the excitation wavelength rising from 270 to $355 \mathrm{~nm}$. Contrasting to aquatic $\mathrm{CDOM}$, the terrestrial humic acids and industrial humic preparations showed lower fluorescence quantum yield, values which practically did not depend on excitation wavelength altered within the range $270-355 \mathrm{~nm}[7,12]$. However, until now, the chemical structure of fluorophores of aquatic CDOM still remains unclear. Yet, to clear the localization of fluorescent species between different structural compounds should be very useful to understand the origin of CDOM fluorescence and its functioning in aquatic environments.

The current work is targeted to fluorescence measurements within the wide range of excitation wavelengths from 230 to $510 \mathrm{~nm}$ focusing on fluorescence quantum yield estimation. We used the reversed-phase high-performance liquid chromatography (RP-HPLC) with online multiwavelength absorbance and fluorescence detections to analyze protein-like and humic-like fluorophores of the CDOM from several lakes of northern Russia with the aim to generalize fluorescence distribution between hydrophilic/hydrophobic parts of CDOM in freshwater lakes.

\section{Materials and Methods}

2.1. CDOM Sample Preparation. The samples of surface water were taken during an expedition (August 2013) in several freshwater lakes located in Karelia, the north of the European part of Russia. The Onego lake is the second largest freshwater body in Europe. In recent years, human impact on the ecosystem of Onego lake has increased, especially in the northwestern part, where several industrial areas are located. The two small ultrafresh lakes of marsh origin, Verhnee and Vodoprovodnoe, are located far from industrial facilities and can serve as a source of CDOM in the absence of anthropogenic load. Water samples were stored in the sealed plastic bottles in the dark at $+4^{\circ} \mathrm{C}$. The $100 \mathrm{ml}$ of original freshwater samples were filtered using cellulose filters (Millipore) with a pore size of $0.45 \mu \mathrm{m}$. $50 \mathrm{~mL}$ of each filtered natural water sample was freeze dried and dissolved in $1.5-3 \mathrm{ml}$ of $10 \mathrm{mM}$ phosphate buffer ( $\mathrm{pH}$ 6.5) prepared by mixing three volumes of $10 \mathrm{mM} \mathrm{Na}_{2} \mathrm{HPO}_{4}$ solution ( $\left.\mathrm{pH} 9.8\right)$ and seven volumes of $10 \mathrm{mM} \mathrm{NaH}_{2} \mathrm{PO}_{4}$ solution ( $\mathrm{pH} 4.5$ ). The concentrated stock solutions of $\mathrm{CDOMs}$ were stored in dark glass vials at $+4^{\circ} \mathrm{C}$ before further spectroscopic and chromatographic analyses.

2.2. UV-Visible Absorption and Fluorescence Emission Spectra. The absorption spectra of original lake water, filtered samples, and CDOM dissolved in phosphate buffer were measured in a quartz cuvette with optical path $1 \mathrm{~cm}$ or $3 \mathrm{~cm}$ using the UV-Vis spectrophotometer Solar PB-2201 (Belarus) within wavelength range $200-900 \mathrm{~nm}$. The $3 \mathrm{~cm}-$ cell was used to measure absorbance more accurately in the visible range of the spectrum. For further applications, all absorbances were related to $1 \mathrm{~cm}$.

The fluorescence emission spectra of CDOM samples were recorded in $1 \mathrm{~cm}$ standard quartz cuvette using a Cary Eclipse fluorescence spectrophotometer (Varian, USA) at different excitation wavelengths from 230 to $510 \mathrm{~nm}$ with the interval of $10 \mathrm{~nm}$ within the emission range of 200-700 $\mathrm{nm}$. In order to minimize the inner-filter effect, all samples were diluted with $0.1 \mathrm{mM}$ phosphate buffer $(\mathrm{pH} 6.5)$ to reach an absorbance of 0.05 at $270 \mathrm{~nm}$.

2.3. Fluorescence Quantum Yield Measurement. The fluorescence quantum yield was measured by the method of the reference compound applied earlier for the samples of CDOM in natural water and commercial humic preparations $[6,7,12]$. As the standard reference compound, quinine sulfate in aqueous $0.05 \mathrm{M} \mathrm{H}_{2} \mathrm{SO}_{4}$ solution was used because it is similar to aquatic humic substances in the shape of emission spectrum with the emission maximum at $450 \mathrm{~nm}$. The fluorescence quantum yield of quinine sulfate is well known and equals to 0.546 , or $54.6 \%$ under excitation at $350 \mathrm{~nm}$ [13]. To obtain a calibration curve, the fluorescence spectra of quinine sulfate were measured at $\lambda_{\mathrm{ex}}=350 \mathrm{~nm}$ and concentrations $3 \cdot 10^{-7}, 5 \cdot 10^{-7}$, and $7 \cdot 10^{-7} \mathrm{M}$.

2.4. Analytical Reversed-Phase High-Performance Liquid Chromatography (RP-HPLC). The CDOM samples dissolved in $10 \mathrm{mM}$ phosphate buffer were analyzed by using an ACQUITY $^{\text {тм }}$ Ultra-Performance Liquid Chromatographic system (Waters Corp., Milford, MA, USA) on analytical

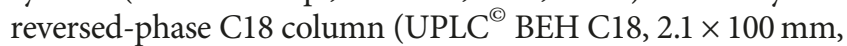
particle size $1.7 \mu \mathrm{m}$, Waters Corp., USA) as the stationary phase. The details of the chromatographic procedure were described in $[14,15]$. The fluorescence of RP-HPLC chromatograms were monitored using an Acquity fluorescence detector (FLR) with $\lambda_{\mathrm{ex}}=270 \mathrm{~nm}$ and emission wavelength range $300-600 \mathrm{~nm}$. The chromatograms with online emission detection at 330 and $450 \mathrm{~nm}$ were analyzed for detection of protein-like and humic-like fluorescence in 


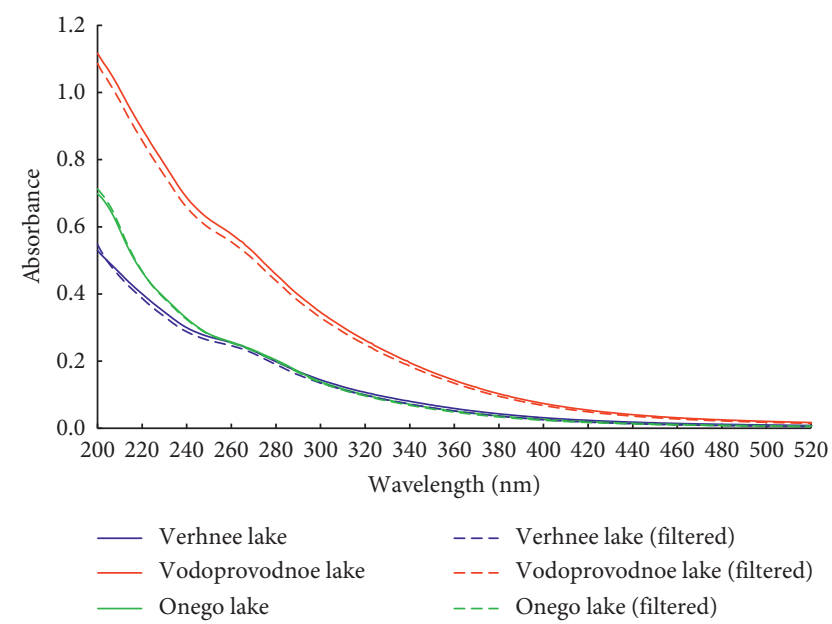

Figure 1: Absorption spectra of surface freshwater from three Karelian lakes, unfiltered (solid lines) and filtered (dashed lines).

the same chromatographic run. The elution rate was $0.3 \mathrm{~mL} / \mathrm{min}$. Methanol and $10 \mathrm{mM}$ phosphate buffer ( $\mathrm{pH} 6.5$ ) were used to form a stepwise gradient. The fluorescence spectra for each RP-HPLC chromatographic peaks' top were extracted from the data of FLR detector.

\section{Results and Discussion}

3.1. UV-Visible Absorption Spectra. The absorption spectra of each original and filtered freshwater sample were similar, demonstrating the low level of organic material in the suspended form presented in the original natural water (Figure 1). All absorption spectra for original water and filtered samples were featureless with a monotonic decline with wavelength increasing from 200 to longer wavelengths with the shoulder located around 260-290 nm. The CDOM content in the lake Vodoprovodnoe was about twice higher than that in two other lakes. The absorption spectra differed in the slope of the curve as well. The absorbance ratio at 230 and $350 \mathrm{~nm}$ (A230/A350) was taken as a quantitative slope measurement. This ratio was used to demonstrate essential differences between the content of aliphatic bonds $\mathrm{C}-\mathrm{C}$, $\mathrm{C}-\mathrm{H}$, and $\mathrm{C}-\mathrm{O}$ in $\mathrm{CDOM}$ of the lakes investigated. The highest value of A230/A350 ratio was noticed for the CDOM in the Onego lake (6.70) and was considerably less (4.77 and 5.44) for the lakes Vodoprovodnoe and Verhnee, respectively. It means that the CDOM of the Onego lake is enriched in aliphatic compounds compared to other two lakes.

\subsection{The Fluorescence Spectra and the Humic-Like Fluores-} cence Emission Maximum as a Function of the Excitation Wavelength. The emission spectra of the CDOM from three Karelian lakes excited at wavelengths from 230 to $510 \mathrm{~nm}$ are presented in Figure 2 after subtraction of the blank emission at each excitation wavelength. We observed that the humiclike fluorescence was prevailing in all CDOM samples. In the excitation region $230-280 \mathrm{~nm}$, the CDOM exhibited broad humic-like bands with the emission maxima from 425 to

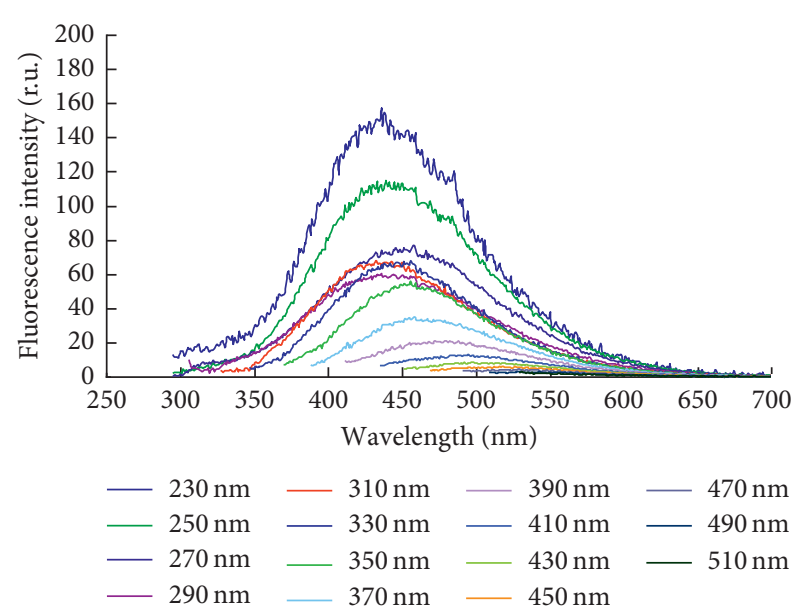

(a)

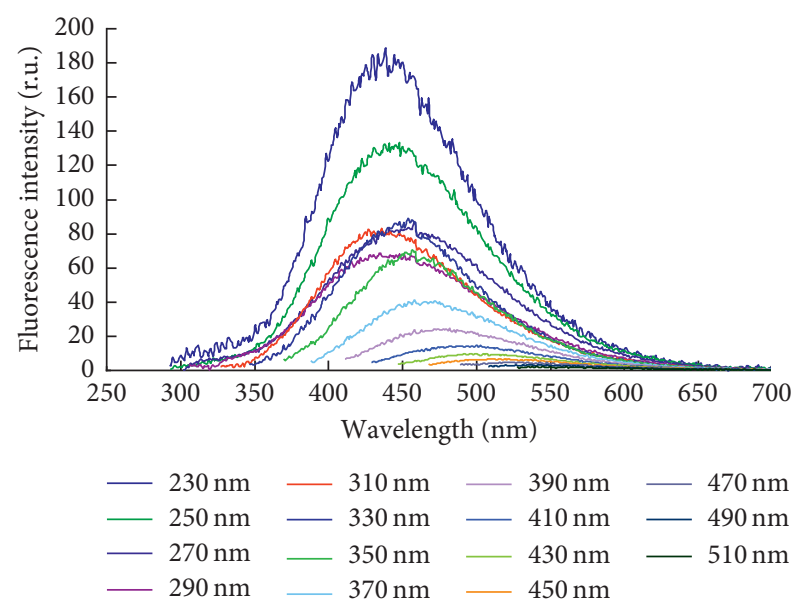

(b)

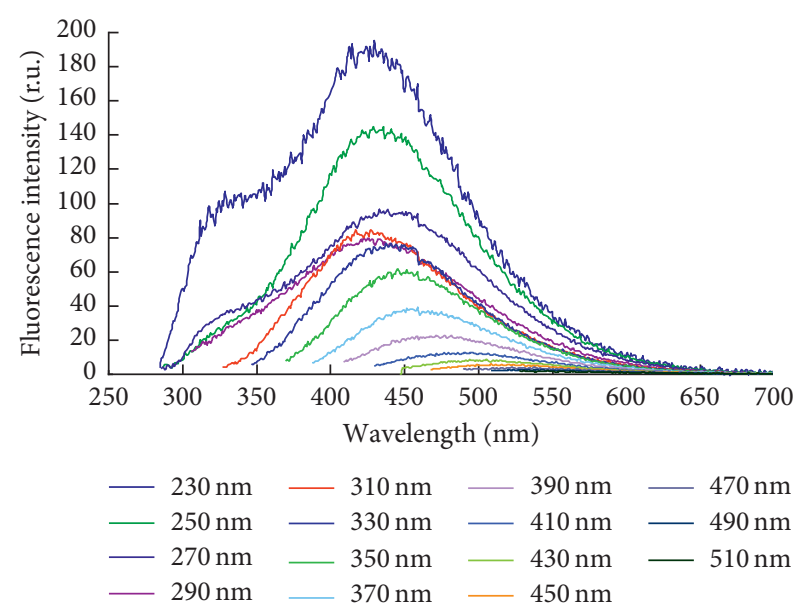

(c)

FIGURE 2: Fluorescence emission spectra of CDOM samples from three Karelian lakes at excitation wavelengths varying from 230 to $510 \mathrm{~nm}$. (a) Verhnee lake. (b) Vodoprovodnoe lake. (c) Onego lake.

$450 \mathrm{~nm}$ and the protein-like fluorescence as a shoulder around $330 \mathrm{~nm}$. The intensity of protein-like emission was higher being excited at $\lambda_{\mathrm{ex}} 230,270$, and $280 \mathrm{~nm}$. The ratio 


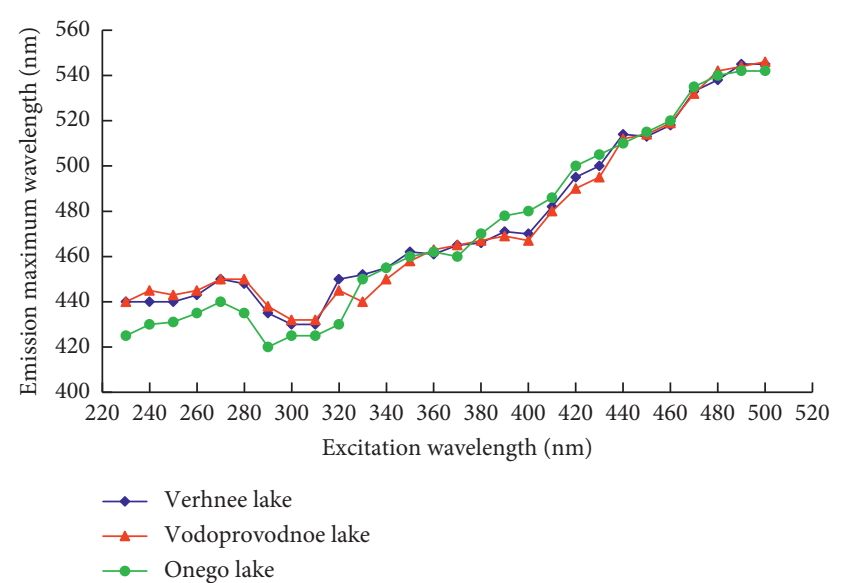

FIgURE 3: Emission maximum wavelength for the humic-like fluorescence as dependence on excitation wavelength for CDOM samples from three Karelian lakes.

between protein-like and humic-like emission intensity was the highest in the Onego lake CDOM and much less in two other samples.

The fluorescence spectra of studied CDOM samples from the lakes manifested a continuous red shift of humiclike emission maximum with increasing $\lambda_{\text {ex }}$ from 310 to $510 \mathrm{~nm}$ (Figure 3), which is a common feature of the CDOM from rivers and coastal margins receiving terrestrial input [16, 17]. Additionally, all studied CDOM samples showed the red shift of humic-like emission maximum with increasing $\lambda_{\mathrm{ex}}$ from 230 to $270-280 \mathrm{~nm}$, within the excitation range not yet analyzed before by other researchers. The so-called "blue shift" was observed with changing $\lambda_{\mathrm{ex}}$ from 270 to $310 \mathrm{~nm}$, which is typical for natural water [5-7]. We did not find any information published in scientific literature about excitation dependency of emission wavelength for the CDOM in freshwater lakes in the excitation range $230-510 \mathrm{~nm}$, so we believe that our results are the first to report this.

\subsection{The Fluorescence Quantum Yield as a Function of Exci-} tation Wavelength. The fluorescence quantum yield values for the CDOM of three freshwater lakes showed nonmonotonous dependence with variation of $\lambda_{\mathrm{ex}}$ from 230 to $510 \mathrm{~nm}$ (Figure 4). The highest fluorescence quantum yields in all the samples (2.3-3.4\%) were obtained with $\lambda_{\mathrm{ex}}$ around $340-360 \mathrm{~nm}$. After increasing $\lambda_{\text {ex }}$ from 370 to $510 \mathrm{~nm}$, quantum yield values decreased monotonically, demonstrating shoulders in 380-410 and $420-470 \mathrm{~nm}$. From $\lambda_{\text {ex }} 230$ to $270-280 \mathrm{~nm}$, the quantum yield values decreased to $1.2-1.7 \%$ and again increased to the maximum at $340-360 \mathrm{~nm}$. It should be noticed that the local minimum was detected in the similar excitation wavelength range (270-290 nm), where the most significant "blue shift" was found. This dependence is in agreement with our previous measurements of quantum yield values on coastal surface waters of the Kara Sea in the excitation region 250-550 nm [8].

The fluorescence quantum yield measurement is sometimes used to characterize aquatic CDOM of marine, riverine, or coastal origin. The overall shape of

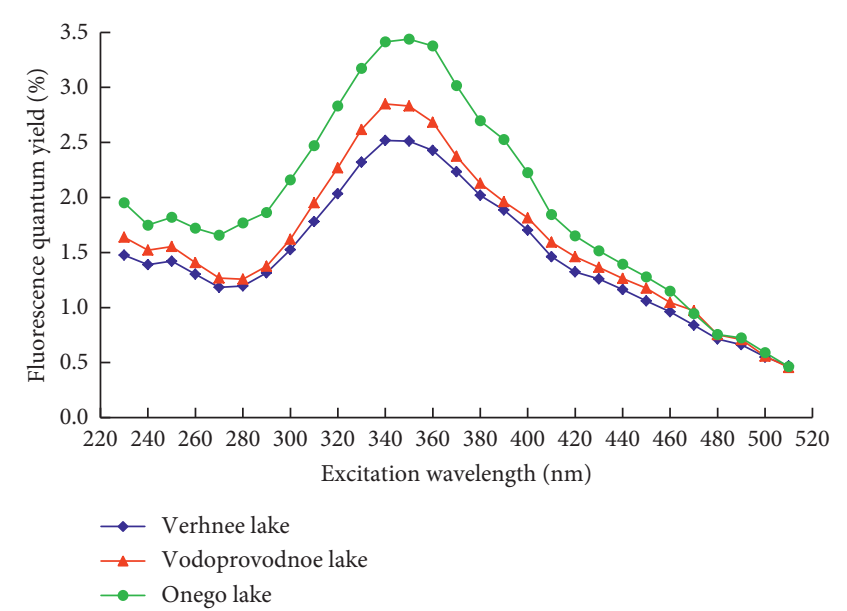

FIgURE 4: Fluorescence quantum yield as a function of excitation wavelength for CDOM samples from different Karelian lakes.

dependencies of fluorescence quantum yield on excitation wavelength was found to be similar in different CDOM samples: the maximum fluorescence efficiencies were obtained at excitation wavelengths between 340 and $380 \mathrm{~nm}$. In [17], the dependence of fluorescence quantum yield on excitation wavelength was used as an evidence of the presence of terrestrial material in natural waters across the Equatorial Atlantic Ocean. The fluorescence quantum yield increased from $280 \mathrm{~nm}$ to a maximum at $370-380 \mathrm{~nm}$ ranging from 1.8 to $2.5 \%$ and decreased monotonically thereafter. The fluorescence quantum yield of CDOM in waters from south Florida, Amazon, and Tamiami rivers and fulvic acids isolated from the Suwannee River was measured by Green and Blough [18]. During investigation performed on water samples from the Equatorial Atlantic Ocean [19], it was established that for excitation wavelengths above $375 \mathrm{~nm}$, the fluorescence quantum yield decreased with decreasing $\lambda_{\text {ex }}$ and the emission maximum shifted continuously to the red. Additionally, maximum at $\sim 340 \mathrm{~nm}$ was observed for the CDOM from a site influenced by the Congo River Plume. The similar behavior of fluorescence quantum yield of CDOM in deep and surface waters of the Norwegian Sea with maxima between 340 and $380 \mathrm{~nm}$ was reported by Wünsch et al. [20]. In whole, our data corroborate with the other studies performed. However, our results presented excitation dependence of the CDOM fluorescence quantum yield in the wavelength range below $280 \mathrm{~nm}$ for freshwater lakes CDOM for the first time. This is important because the minimum fluorescence quantum yield around excitation at $280 \mathrm{~nm}$ was found. Moreover, it is valuable for further interpretation of CDOM fluorescence origin because it is the same spectral range of excitation where the blue shift of CDOM fluorescence emission is normally observed.

3.4. The Reversed-Phase High-Performance Liquid Chromatography (RP-HPLC) with Online Absorbance and Fluorescence Detections. The RP-HPLC with stepwise gradient 


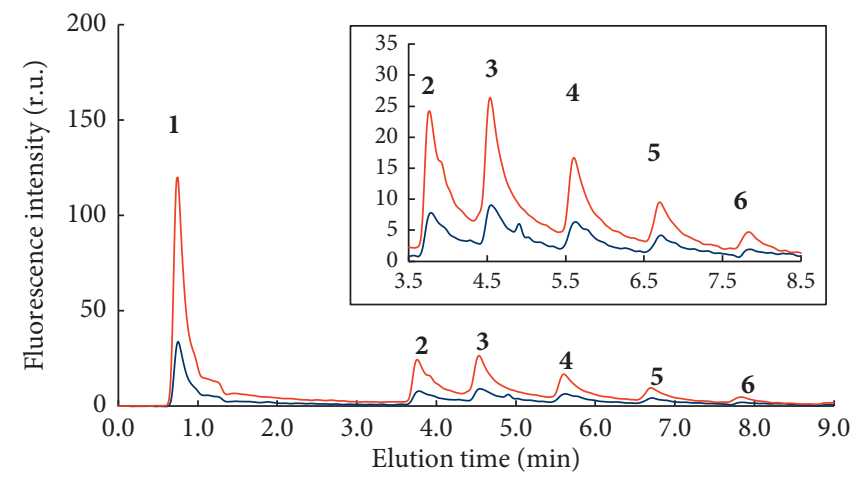

(a)

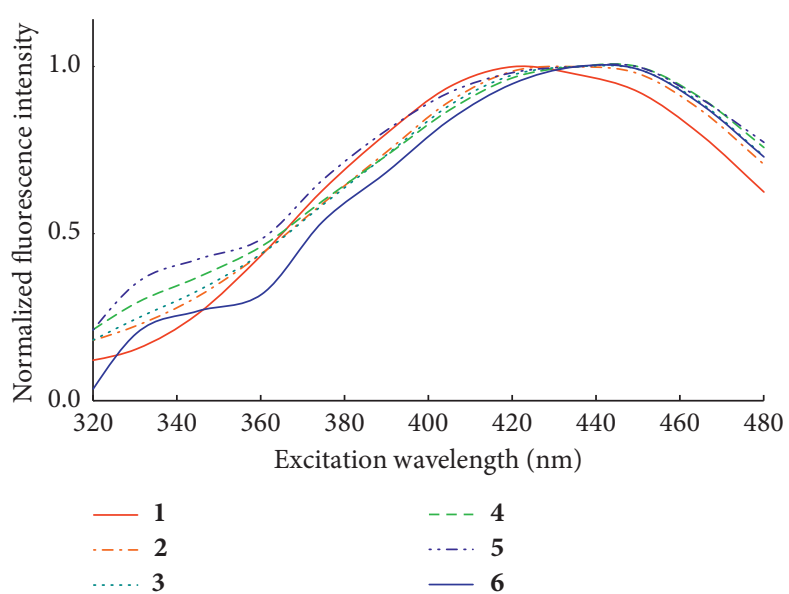

(c)

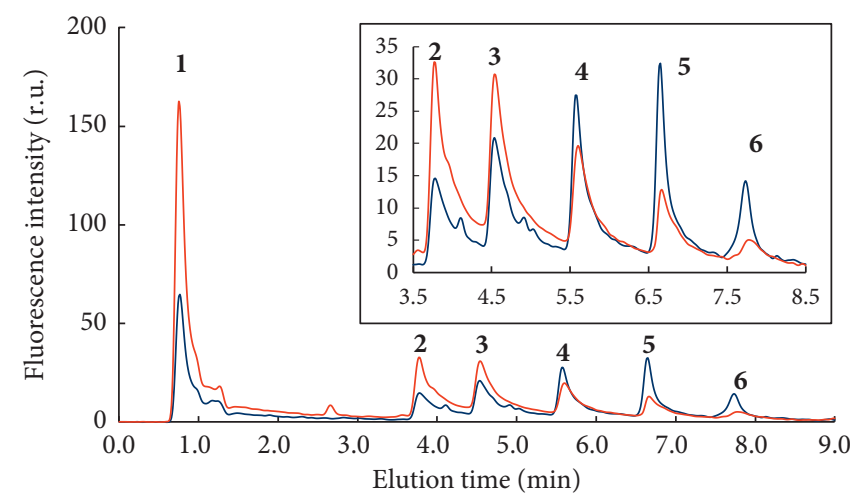

(b)
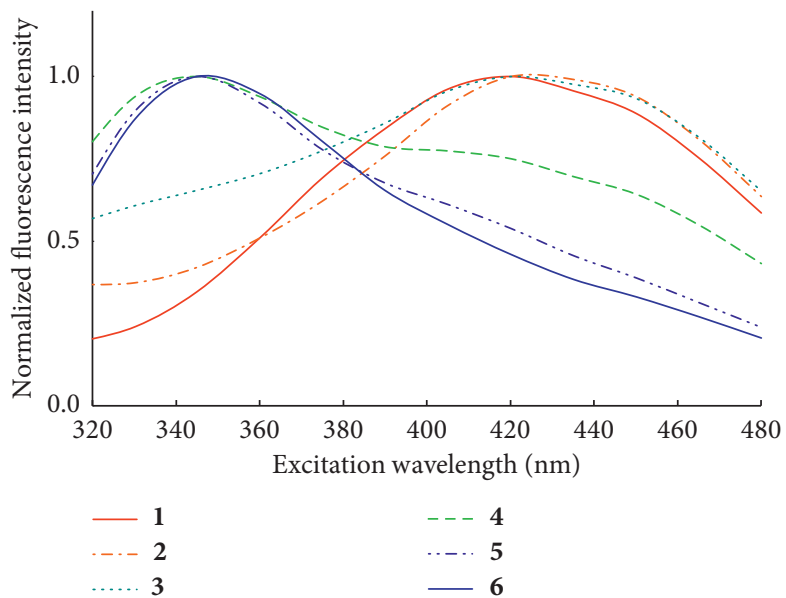

(d)

Figure 5: RP-HPLC chromatograms of CDOM from the Verhnee (a) and Onego (b) lakes with online fluorescence detection at excitation/emission wavelength pairs $270 / 450 \mathrm{~nm}$ (red lines) and 270/350 nm (blue lines) for detection of humic-like and protein-like fluorescence, respectively. Inset zoom shows the zone of chromatograms from 3.5 to $8.5 \mathrm{~min}$. Normalized emission spectra of the peaks \#1-6 of fractionated CDOM from the Verhnee (c) and Onego (d) lakes. The CDOM from the Vodoprovodnoe lake demonstrated similar chromatograms and emission spectra with that of the Verhnee lake.

formation using methanol and aqueous phosphate buffer gave possibility to map the CDOM in terms of distribution of hydrophilic/hydrophobic chromophores. The chromatograms with online absorbance detection resolved six peaks with different hydrophobic properties. The hydrophobicity of peaks increased from the first to the last eluted peak due to the increase of methanol concentration in the stepwise separation procedure. In our previous study [21], we have found that the highest content of hydrophilic fraction was in the CDOM from the Onego lake. In this research, we have confirmed this finding for all studied lakes by registration of online fluorescence (Figure 5). The fluorescence detection at $\lambda_{\text {ex }}=270 \mathrm{~nm}$ has shown that the CDOM in all three lakes contained humic-like fluorophores, for which the emission maxima depended on hydrophilic/hydrophobic properties. The most intensive humic-like fluorescence with emission maximum at $420 \mathrm{~nm}$ was found for the first hydrophilic peak in all three samples. Along with increasing the hydrophobicity of chromatographic fraction, the humic-like fluorescence maximum shifted in $30 \mathrm{~nm}$ towards longer wavelengths. So RP-HPLC revealed the presence of at least two humic-like fluorophores with different emission maxima (420 or $450 \mathrm{~nm}$ ) depending on their hydrophobicity. Fluorescence measurements were made not only for humic-like fluorescence but also for protein-like fluorescence. The fluorophore emitting a maximum at around $345 \mathrm{~nm}$ was found in the most hydrophobic fractions of CDOM. The highest amplitude of protein-like fluorescence was detected in the CDOM chromatographic peaks \#4-6 of the Onego lake (Figures 5(b) and 5(d)), while in CDOM from two other lakes of marsh origin, the protein-like fluorophores were found in the peaks \#5-6 only in the trace amounts compared to humic-like fluorophores (Figures 5(a) and 5(c)).

\subsection{Observation of "Hidden" Fluorophores Emitting Protein-} Like Fluorescence. The application of the RP-HPLC revealed "hidden" protein-like fluorophores in hydrophobic CDOM peaks. The local minimum in fluorescence quantum yield dependency on excitation wavelength for freshwater CDOM was found at $\lambda_{\mathrm{ex}} \sim 270-280 \mathrm{~nm}$, where the "blue shift" of CDOM fluorescence emission was typically observed as well 
Journal of Spectroscopy

[5-7]. On the contrary, the RP-HPLC with online fluorescence detection has shown that the intensive humic-like fluorescence was found at all hydrophilic and hydrophobic chromatographic peaks (Figure 5). It should be stressed that the intensity of protein-like fluorescence increased with the increase of peaks' hydrophobicity, while the humic-like fluorescence decreased. This effect was more pronounced in the Onego lake CDOM (Figures 5(b) and 5(d)). High amount of hydrophobic "hidden" protein-like fluorophores (i.e., fluorophores clearly detected by RP-HPLC but not so obviously visible in the original $\mathrm{CDOM}$ fluorescence spectra before fractionation) is one of the reasons of humic-like fluorescence quenching. We believe that the minimal CDOM fluorescence quantum yield observed at $\lambda_{\text {ex }} \sim 270-280 \mathrm{~nm}$ could be partially resulting from absorption of light by chromophoric groups similar to aromatic amino acids, short peptides, or proteins and thus leading to reduction in humic-like fluorescence excited at this wavelength range.

\section{Conclusions}

Fluorescence properties of natural CDOM from three Karelian freshwater lakes were examined within the excitation wavelength range $230-510 \mathrm{~nm}$, and the influence of $\lambda_{\mathrm{ex}}$ on fluorescence quantum yield and wavelength of emission maximum was determined. For all studied CDOM samples, the "blue shift" of humic-like fluorescence was observed at $\lambda_{\mathrm{ex}}$ from 270 to $310 \mathrm{~nm}$. On the contrary, a continuous "red shift" in emission maximum with increasing excitation wavelength was observed at $\lambda_{\text {ex }}$ from 230 to $270 \mathrm{~nm}$ and $\geq 310 \mathrm{~nm}$. The quantum yield of CDOM fluorescence decreased starting from excitation at $230 \mathrm{~nm}$, showing a minimum at $270-280 \mathrm{~nm}$, then reaching a maximum at $340-360 \mathrm{~nm}$ and further decreasing towards longer excitation wavelengths. These results, for the first time, demonstrated the excitation-wavelength dependence of fluorescence quantum yield in the spectral range of excitation below $280 \mathrm{~nm}$ for freshwater CDOM. Analytical RPHPLC with multiwavelength fluorescence and absorbance detectors was used to characterize CDOM in freshwater lakes and to determine distribution of fluorophores between hydrophilic/hydrophobic CDOM parts. The intensive humiclike fluorescence was found at all hydrophilic and hydrophobic chromatographic peaks, while the protein-like fluorescence was detected only in the most hydrophobic peaks; the intensity of protein-like fluorescence increased with the increase of peaks' hydrophobicity, while the humic-like fluorescence decreased. These results are well consistent with the formation of supramolecular assemblies by the CDOM molecules, likely controlled by association of low-molecular size components. The distribution of humic-like and protein-like fluorophores within the CDOM provides detailed information that may help to better trace the origin of $\mathrm{CDOM}$ and its biogeochemical transformations in the environment.

\section{Data Availability}

The data used to support the findings of this study are available from the corresponding author upon request.

\section{Conflicts of Interest}

The authors declare that they have no conflicts of interest.

\section{Acknowledgments}

The authors express their gratitude to Dr. Elena Krasnova, Dr. Dmitriy Voronov, and Professor Igor Glushko for their enthusiastic help in water sampling and very fruitful discussions. The authors thank the administration and the staff of N. A. Pertzov White Sea Biological Station of Lomonosov Moscow State University for their kind support during the field work. This work was financially supported by the Russian Foundation for Basic Research (RFBR) (Grant no. 18-016-00078).

\section{References}

[1] D. P. Häder, C. E. Williamson, S. A. Wängberg et al., "Effects of UV radiation on aquatic ecosystems and interactions with other environmental factors," Photochemical and Photobiological Sciences, vol. 14, no. 1, pp. 108-26, 2015.

[2] P. G. Coble, S. A. Green, N. V. Blough, and R. B. Gagosian, "Characterisation of dissolved organic matter in the Black Sea by fluorescence spectroscopy," Nature, vol. 348, no. 6300, pp. 432-435, 1990.

[3] P. G. Coble, R. G. M. Spencer, A. Bakeret et al., "Aquatic organic matter fluorescence," in Aquatic Organic Matter Fluorescence, P. G. Coble, J. Lead, A. Baker, D. A. Reynolds, and R. G. M. Spencer, Eds., pp. 75-122, Cambridge University Press, New York, NY, USA, 2014.

[4] O. F. X. Donard, M. Lamotte, C. Belin et al., "High-sensitivity fluorescence spectroscopy of Mediterranean waters using a conventional or a pulsed laser excitation source," Marine Chemistry, vol. 27, no. 1-2, pp. 117-136, 1989.

[5] O. M. Gorshkova, A. S. Milukov, S. V. Patsayeva et al., "Fluorescence of DOM nanoparticles in natural water," in Proceedings of SPIE, Atomic and Molecular Pulsed Lasers VI, vol. 6263, pp. 248-255, Tomsk, Russian Federation, May 2006.

[6] A. S. Milyukov, S. V. Patsaeva, V. I. Yuzhakov, O. M. Gorshkova, and E. M. Prashchikina, "Fluorescence of nanoparticles of organic matter dissolved in natural water," Moscow University Physics Bulletin, vol. 62, no. 6, pp. 368-372, 2007.

[7] D. M. Shubina, O. M. Gorshkova, S. V. Patsaeva et al., "The "blue shift" of emission maximum and the fluorescence quantum yield as quantitative spectral characteristics of dissolved humic substances," EARSeL eProceedings, vol. 9, pp. 13-21, 2010.

[8] A. N. Drozdova, S. V. Patsaeva, and D. A. Khundzhua, "Fluorescence of dissolved organic matter as a marker for distribution of desalinated waters in the Kara Sea and bays of Novaya Zemlya archipelago," Oceanology, vol. 57, no. 1, pp. 41-47, 2017.

[9] D. Khundzhua, S. Patsaeva, V. Terekhova et al., "Spectral characterization of fungal metabolites in aqueous medium with humus substances," Journal of Spectroscopy, vol. 2013, Article ID 538608, 7 pages, 2013.

[10] E. Parlanti, K. Woerz, L. Geoffroy et al., "Dissolved organic matter fluorescence spectroscopy as a tool to estimate biological activity in a coastal zone submitted to anthropogenic inputs," Organic Geochemistry, vol. 31, no. 12, pp. 1765-1781, 2000. 
[11] R. Del Vecchio and N. V. Blough, "On the origin of the optical properties of humic substances," Environmental Science and Technology, vol. 38, no. 14, pp. 3885-3891, 2004.

[12] O. Gosteva, A. A. Izosimov, S. V. Patsaeva, V. I. Yuzhakov, and O. S. Yakimenko, "Fluorescence of aqueous solutions of commercial humic products," Journal of Applied Spectroscopy, vol. 78, no. 6, pp. 884-891, 2012.

[13] R. A. Velapoldi and K. D. Mielenz, A Fluorescence Standard Reference Material: Quinine Sulfate Dihydrate, NBS Spec Publ. 260-64, National Bureau of Standards, Washington DC, USA, 1980.

[14] O. E. Trubetskaya, C. Richard, and O. A. Trubetskoj, "Evaluation of Suwannee River NOM electrophoretic fractions by RP-HPLC with online absorbance and fluorescence detection," Environmental Science and Pollution Research, vol. 22, no. 13, pp. 9989-9998, 2015.

[15] O. E. Trubetskaya, C. Richard, and O. A. Trubetskoj, "High amounts of free aromatic amino acids in the protein-like fluorescence of water-dissolved organic matter," Environmental Chemistry Letters, vol. 14, no. 4, pp. 495-500, 2016.

[16] C. A. Stedmon, S. Markager, and R. Bro, "Tracing dissolved organic matter in aquatic environments using a new approach to fluorescence spectroscopy," Marine Chemistry, vol. 82, no. 3-4, pp. 239-254, 2003.

[17] A. A. Andrew, R. Del Vecchio, A. Subramaniam, and N. V. Blough, "Chromophoric dissolved organic matter $(\mathrm{CDOM})$ in the Equatorial Atlantic Ocean: Optical properties and their relation to CDOM structure and source," Marine Chemistry, vol. 148, pp. 33-43, 2013.

[18] S. A. Green and N. V. Blough, "Optical absorption and fluorescence properties of chromophoric dissolved organic matter in natural waters," Limnology and Oceanography, vol. 39, no. 8, pp. 1903-1916, 1994.

[19] E. S. Boyle, N. Guerriero, A. Thiallet et al., "Optical properties of humic substances and CDOM: relation to structure," Environmental Science and Technology, vol. 43, no. 7, pp. 2262-2268, 2009.

[20] U. Wünsch, K. R. Murphy, and C. Stedmon, "Fluorescence quantum yields of natural organic matter and organic compounds: implications for the fluorescence-based interpretation of organic matter composition," Frontiers in Marine Science, vol. 2, p. 98, 2015.

[21] D. A. Khundzhua, S. V. Patsaeva, O. A. Trubetskoj, and O. E. Trubetskaya, "An analysis of dissolved organic matter from freshwater Karelian lakes using reversed-phase highperformance liquid chromatography with online absorbance and fluorescence analysis," Moscow University Physics Bulletin, vol. 72, no. 1, pp. 68-75, 2017. 

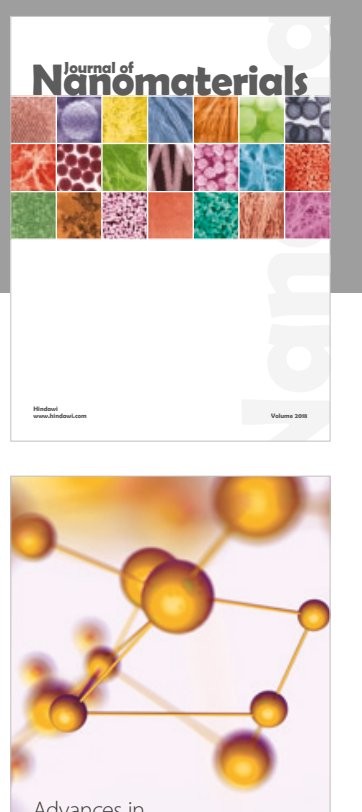

Physical Chemistry
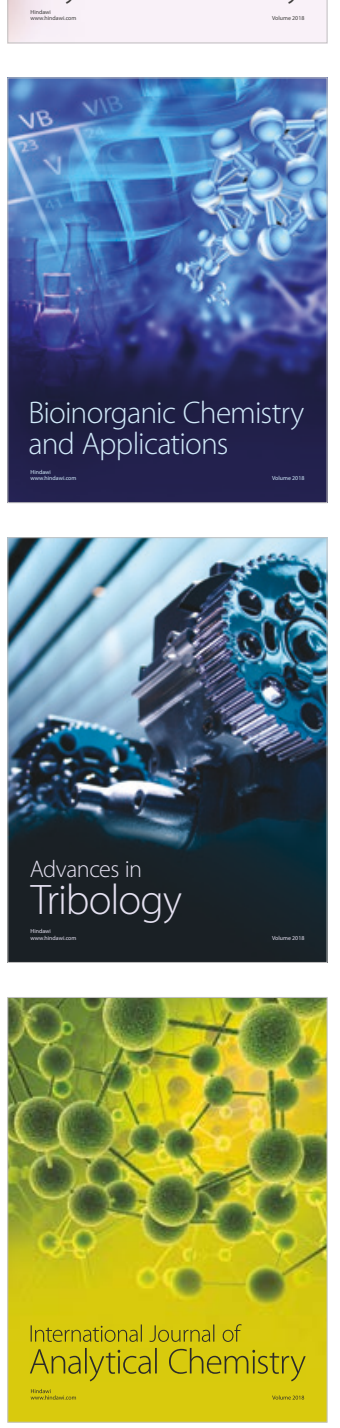

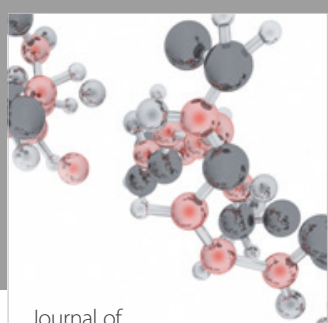

Analytical Methods

in Chemistry

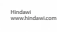

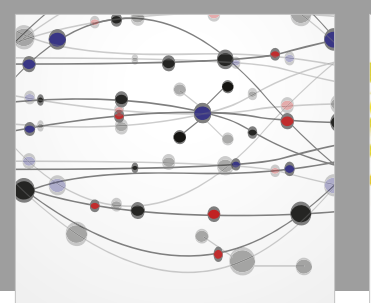

The Scientific World Journal

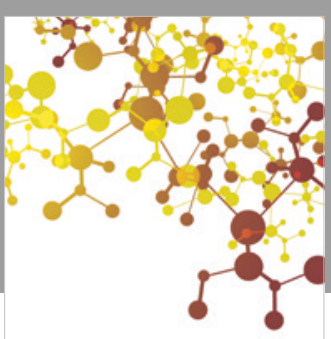

Journal of

Applied Chemistry
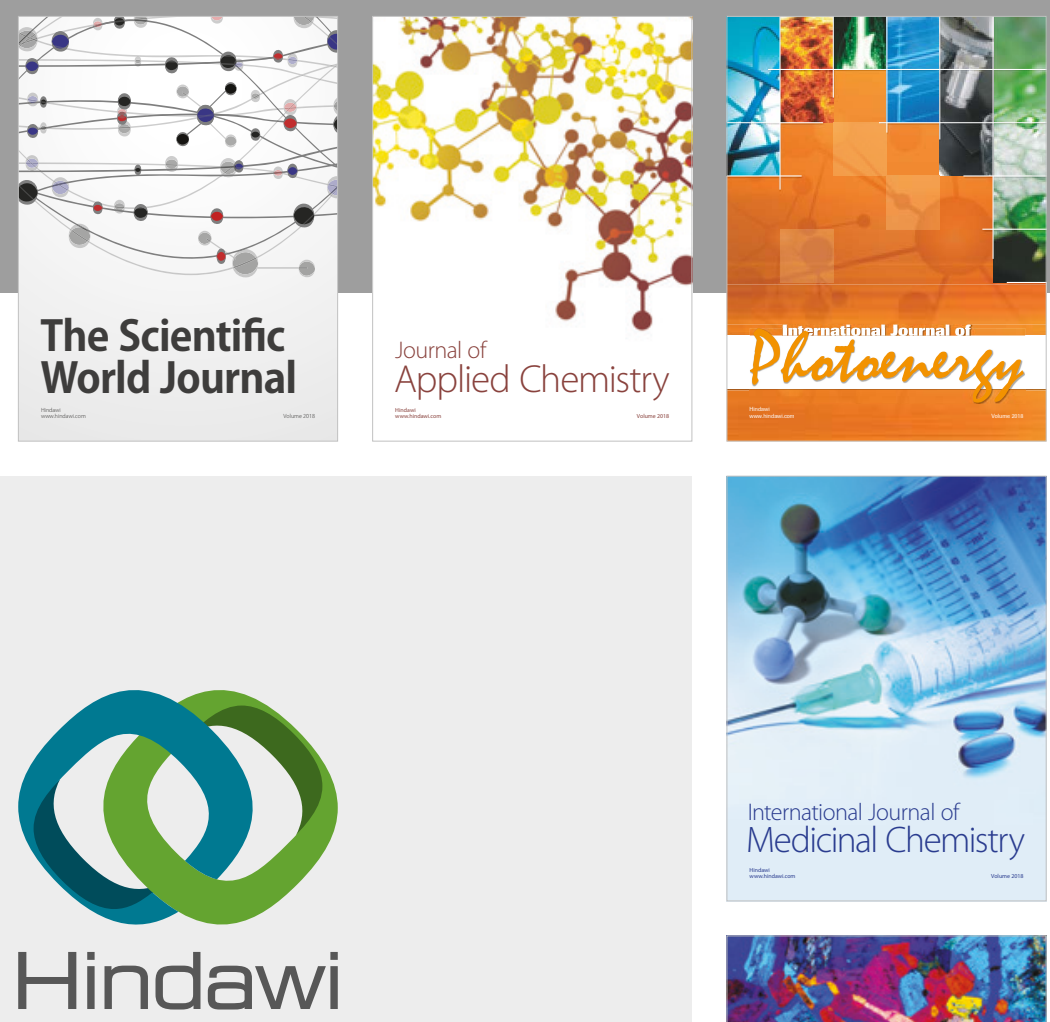

Submit your manuscripts at

www.hindawi.com
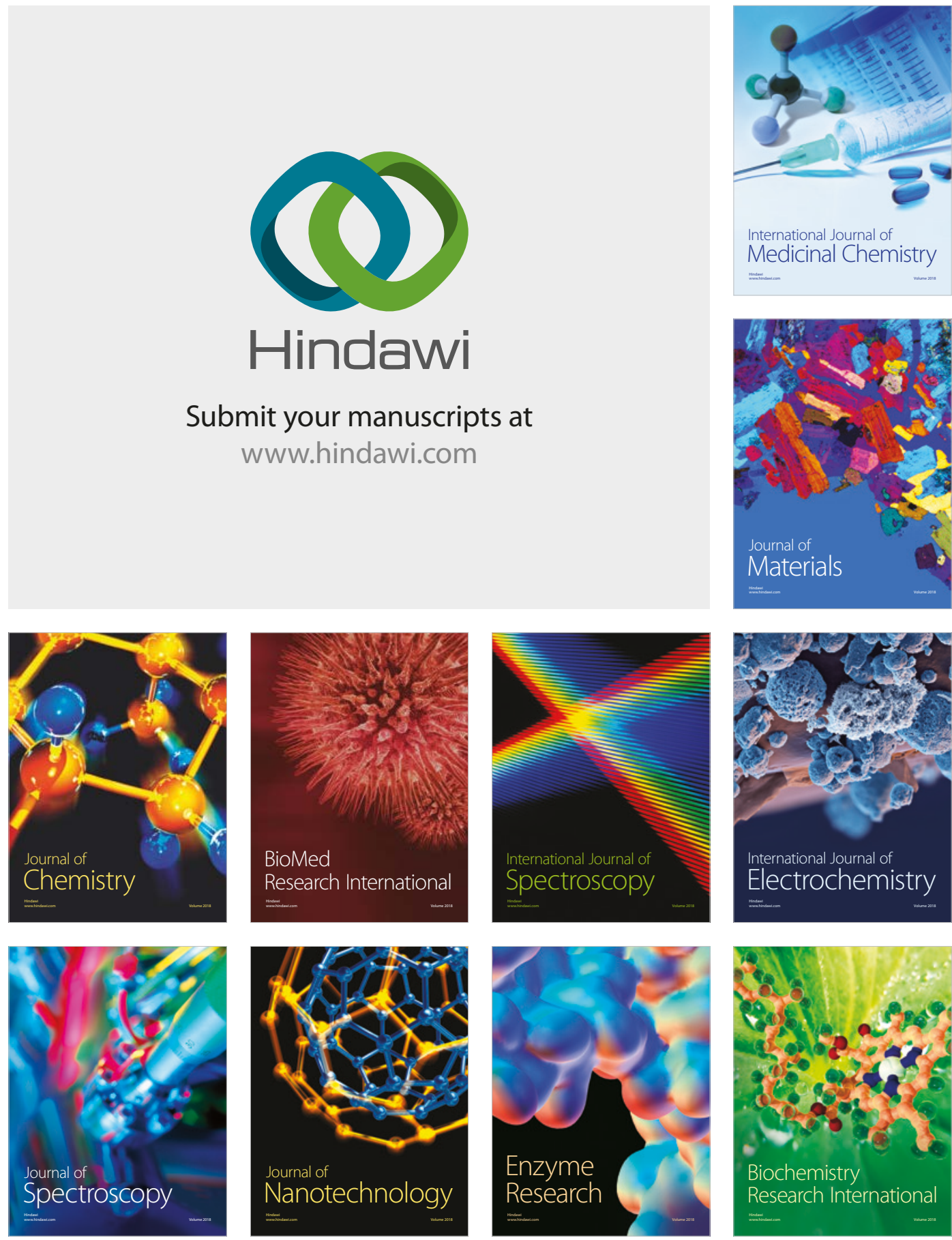
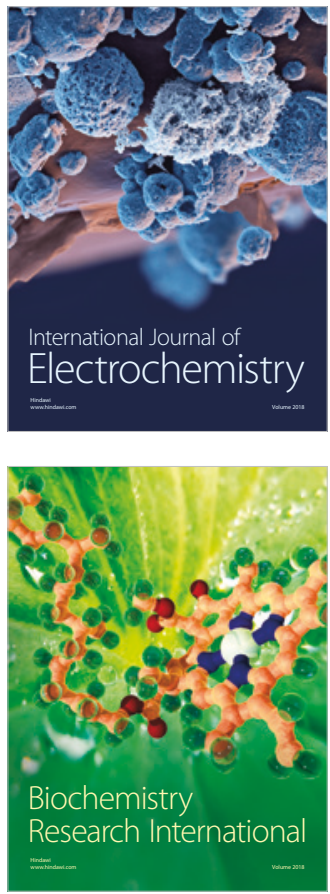